\title{
Inter-relação entre metodologias didáticas, motivos e aprendizagem em Bioquímica
}

\section{Interrelationship between didactic methodologies, motives and learning in biochemistry}

Vanessa Aina Person (vaynaperson@ hotmail.com)

Universidade Federal de Santa Maria (UFSM)

João Batista Teixeira da Rocha (jbtrocha@yahoo.com.br) Universidade Federal de Santa Maria (UFSM)

Resumo: A Bioquímica é uma disciplina básica de inúmeros cursos de graduação, a qual estuda as relações entre biomoléculas e reações químicas que ocorrem em diferentes organismos vivos nos estados de saúde e de doença. O domínio dos conhecimentos bioquímicos é avaliado como complexo e desafiador principalmente pela necessidade de abstração para compreensão conceitual. O objetivo deste trabalho foi analisar quais são as modalidades didáticas que estão sendo utilizadas para ensinar Bioquímica no Brasil, e, porque estas modalidades poderiam ser consideradas motivadoras de ensino e de aprendizagem, tendo como embasamento teórico a Teoria da Atividade e a psicologia Histórico-cultural. Foram analisados 36 artigos publicados na Revista de Ensino de Bioquímica (REB), entre 2015 e 2019. Emergiram da análise as categorias: motivos relacionados à interação social, motivos relacionados à aprendizagem ativa e motivos relacionados ao desempenho acadêmico. A maioria dos artigos descreveram processos ativos de ensino, apontando para uma tendência focada no aluno como protagonista da aprendizagem.

Palavras-chave: Educação em Bioquímica; metodologias; aprendizagem ativa; Teoria da atividade.

\begin{abstract}
Biochemistry is a basic discipline of numerous undergraduate courses, which studies the relationships between biomolecules and chemical reactions that occur in different living organisms in health and disease states. The mastery of biochemical knowledge is assessed as complex and challenging mainly by the need for abstraction for conceptual understanding, generating great concern for those who teach. The aim of this paper was to analyze what are the didactic modalities that are being used to teach biochemistry in Brazil, and why these modalities are considered motivating of teaching and learning, having as theoretical basis the Activity Theory and the Historical-cultural psychology. We analyzed 36 articles published in the Journal of Biochemistry Education (REB), between 2015 and 2019. The following categories emerged from the analysis: motives related to social interaction, motives related to active learning and motives related to academic performance. Most articles described active teaching processes, pointing to a student-focused tendency as a protagonist of learning.
\end{abstract}

Keywords: Biochemistry Education; methodologies; active learning; activity theory. 


\section{INTRODUÇÃO}

Um dos grandes desafios do ensino é desenvolver nos alunos a capacidade de refletir/pensar criticamente, dando sentido aos conhecimentos que estão sendo abordados e criando possibilidades de aprendizagem. A Bioquímica enquanto disciplina, é considerada de difícil compreensão, pois exige um alto grau de abstração ao tratar de fenômenos ao nível molecular (isto é, atômico, submicroscópico e microscópico) que ocorrem nos organismos vivos nos estados de saúde e de doença. Além disto, num levantamento recente observamos que as percepções e avaliação sobre a disciplina de Bioquímica por estudantes de graduação, de diversos cursos, foi bastante negativa, mostrando que as aulas de Bioquímica devem ser repensadas e que os conhecimentos básicos devem ser aprimorados (NOGARA, et al, 2018).

Esta dificuldade pode estar relacionada com a maneira de ensinar e de aprender, justificando a busca por metodologias de ensino diferenciadas, que atraiam a atenção, colaboração e participação ativa dos alunos. Concordamos com Sforni (2004, p. 13), ao considerar que não existe ensino único capaz de desencadear aprendizagem generalizada, mas "uma variedade de formas de transmissão de saber que podem ser mais ou menos competentes na promoção do desenvolvimento cognitivo". No entanto, compreendemos que a apropriação do conhecimento não é um processo imediato que ocorre pela simples utilização de uma metodologia, mas deve despertar no aluno um sentimento de necessidade (motivação), ser mediada pelo professor e ter uma intencionalidade.

Buscamos analisar as modalidades didáticas utilizadas para ensinar Bioquímica no Brasil e compreender porque elas são ou não consideradas motivadoras de ensino e aprendizagem em Bioquímica, bem como propor uma reflexão sobre o significado dos conceitos motivo/motivação no âmbito educacional levando em consideração a dinâmica do comportamento e desenvolvimento psíquico humano (LEONTIEV, 1978, 1985; VIGOTSKI, 2001, 2002).

\section{OS MOTIVOS NAS ATIVIDADES DE ENSINO E APRENDIZAGEM}


A psicologia histórico-cultural do desenvolvimento humano proposta por Vigotski, Leontiev e outros colaboradores, aborda aspectos relacionados aos processos de aprendizagem, linguagem e desenvolvimento (VIGOTSKI; LURIA e LEONTIEV, 2016) sob o referencial teórico-metodológico do materialismo histórico-dialético (CALVE; ROSSLER; SILVA, 2015). Assim, a base do desenvolvimento psíquico humano é social, o homem é considerado produto da apropriação da cultura e da sociedade, o qual se desenvolve principalmente pelo uso da linguagem, instrumentos e de seus significados. Neste contexto, as atividades ocorrem num sistema de relações sociais que estão associadas a processos de cooperação, organizadas coletivamente e reguladas pela linguagem - o agir comunicativo (BONOTTO, SCHELLER, 2018).

Nesta perspectiva, as atividades de ensino e aprendizagem são atividades sociais de produção de conhecimento científico bem como de desenvolvimento psíquico, sendo fundamental mobilizar o pensamento dos alunos para transformá-lo em ação mental. A motivação nesse contexto é considerada um estímulo para os estudantes participarem das atividades propostas pelo professor. Conforme Marino Filho (2011),

[...] não basta que haja à disposição dos alunos os objetos, ou conteúdos disciplinares, para que eles se envolvam cognitivamente de forma produtiva e desenvolvedora. Há que se produzir uma atividade que crie a necessidade de envolvimento do aluno e que ela faça sentido para ele, no conjunto das suas ações, e que este sentido possa reconhecer-se como vital para o seu desenvolvimento (MARINO, FILHO, p.59, 2011).

Leontiev (1978) propõe que a atividade é em termos mais gerais, uma forma de agir mediada por uma ferramenta (material ou intelectual) e conduzida por uma necessidade. No entanto, em estudos posteriores, Leontiev (1985, p. 83 [trad. nossa]) destacou que "na realidade sempre estamos na presença de atividades específicas, cada uma das quais responde a uma determinada necessidade do sujeito". O autor ressalta que o mais importante que distingue uma atividade de outra é o objeto da atividade, o seu motivo, que pode ser externo ou ideal.

Nesta perspectiva, distintos motivos podem emergir das atividades de ensino e aprendizagem, por exemplo, podem ser motivos eficazes ou apenas compreensíveis. De acordo com Leontiev (1978, 1985), os motivos apenas compreensíveis são aqueles que não geram significado real para quem realiza uma atividade, ou seja, mesmo sabendo que existe uma necessidade por detrás da atividade proposta, não há sentido pessoal para realizá-la. Já nos motivos realmente eficazes, as atividades são geradoras de sentido pessoal, o autor aponta que "ao satisfazer a sua necessidade de conhecimento, o 
homem pode fazer de um conceito o seu conceito, isto é, apropriar-se de sua significação" (LEONTIEV, 1978, p. 168[grifo do autor]).

Por exemplo, estudar Bioquímica pode ser apenas um meio de não reprovar nesta disciplina, sendo, portanto, um motivo apenas compreendido. Porém, se o aluno estuda para compreender o que ocorre nos níveis moleculares, relacionando com a sua própria vida e futura profissão, o conteúdo estudado fará outro sentido para ele. Consequentemente as metodologias didáticas seguem uma lógica parecida, elas podem ser realizadas mecanicamente pelo estudante apenas para realizar o que lhe foi proposto, ou elas podem auxiliar efetivamente na aprendizagem.

Assim é importante conhecer os motivos que conduzem a realização das atividades propostas. Dependendo da intencionalidade do professor e da necessidade despertada no aluno, o uso de metodologias didáticas diferenciadas pode ou não desencadear o aprendizado.

\section{METODOLOGIA}

A metodologia utilizada neste trabalho é de caráter qualitativo bibliográfico, que se caracteriza por ser aquela realizada a partir de registros disponíveis, decorrentes de pesquisas anteriores. Conforme Severino (2007) neste processo utiliza-se

[...] dados ou de categorias teóricas já trabalhadas por outros pesquisadores e devidamente registrados. Os textos tornam-se fontes dos temas a serem pesquisados. O pesquisador trabalha a partir das contribuições dos autores dos estudos analíticos constantes dos textos (SEVERINO, 2007, p. 122).

Para realizar nossa análise, selecionamos Revista de Ensino de Bioquímica (REB), que está vinculada a Sociedade Brasileira de Bioquímica e Biologia Molecular (SBBq). Conforme o website da REB, a revista é um meio de divulgar pesquisas em ensino de Bioquímica, Biologia Molecular e áreas afins, contribuindo para os avanços científicos, tecnológicos e pedagógicos.

Utilizamos como critério de inclusão apenas os artigos publicados nos últimos 5 anos (2015-2019), excluindo as edições especiais (resumos publicados das reuniões anuais SBBq) deste período. Neste intervalo de tempo foram publicados 49 artigos alocados nas seções "Inovações Educacionais", "Pesquisa em Ensino", "REB Na Escola", "Imagem Pública e Divulgação Científica". 
Nosso objetivo inicial foi verificar quais são as metodologias didáticas utilizadas atualmente para ensinar Bioquímica no Brasil. Após a primeira leitura, percebemos que muitas das pesquisas publicadas faziam alguma correlação entre a metodologia didática utilizada e a motivação, emergindo assim, outro questionamento: por que os pesquisadores consideram as metodologias didáticas utilizadas como motivadoras de ensino e aprendizagem em Bioquímica?

Para a segunda etapa da pesquisa utilizamos como ferramenta analítica a Análise Textual Discursiva (ATD), que consiste em três estágios:

1. Desmontagem dos textos: também denominado de processo de unitarização, implica examinar os materiais em seus detalhes, fragmentando-os no sentido de atingir unidades constituintes [...]

2. Estabelecimento de relações: processo denominado de categorização, implicando construir relações entre as unidades de base, combinando-as e classificando-as no sentido de compreender como esses elementos unitários podem ser reunidos na formação de conjuntos mais complexos, as categorias.

3. Captando o novo emergente: a intensa impregnação nos materiais da análise desencadeada pelos dois estágios anteriores possibilita a emergência de uma compreensão renovada do todo. [...] O metatexto resultante desse processo representa um esforço em explicitar a compreensão que se apresenta como produto de uma nova combinação dos elementos construídos ao longo dos passos anteriores (MORAES, 2003, p. 192 [grifos do autor]).

Por meio da utilização da ATD e tendo como embasamento teórico a psicologia histórico-cultural do desenvolvimento humano emergiram as categorias: motivos relacionados à interação social; motivos relacionados à aprendizagem ativa e motivos relacionados ao desempenho acadêmico que serão descritas e analisadas na sequência.

\section{RESULTADOS E DISCUSSÃO}

No período de 2015 a 2019 foram publicados na REB 49 artigos, sendo que 36 deles continham em algum momento as palavras "motivo", "motivação", "motivador" e/ou "motivados" (Quadro 1).

Quadro 1- Total de artigos publicados na REB entre 2015 a 2019.

\begin{tabular}{|c|c|c|}
\hline Ano & Total de artigos & Motivo/motivação/motivador/motivados \\
\hline 2015 & 10 & 7 \\
\hline 2016 & 12 & 10 \\
\hline 2017 & 11 & 8 \\
\hline 2018 & 10 & 6 \\
\hline
\end{tabular}




\begin{tabular}{|c|c|c|}
\hline 2019 & 6 & 5 \\
\hline TOTAL & 49 & 36 \\
\hline
\end{tabular}

Fonte: os autores, 2019.

No quadro 2 destacamos as metodologias encontradas, sendo possível observar que as atividades lúdicas, o uso de softwares e a experimentação foram as mais citadas e a educação continuada, fóruns de discussão, apresentação de seminários, mapas conceituais e sequências didáticas as metodologias menos citadas.

Quadro 2- Metodologias didáticas

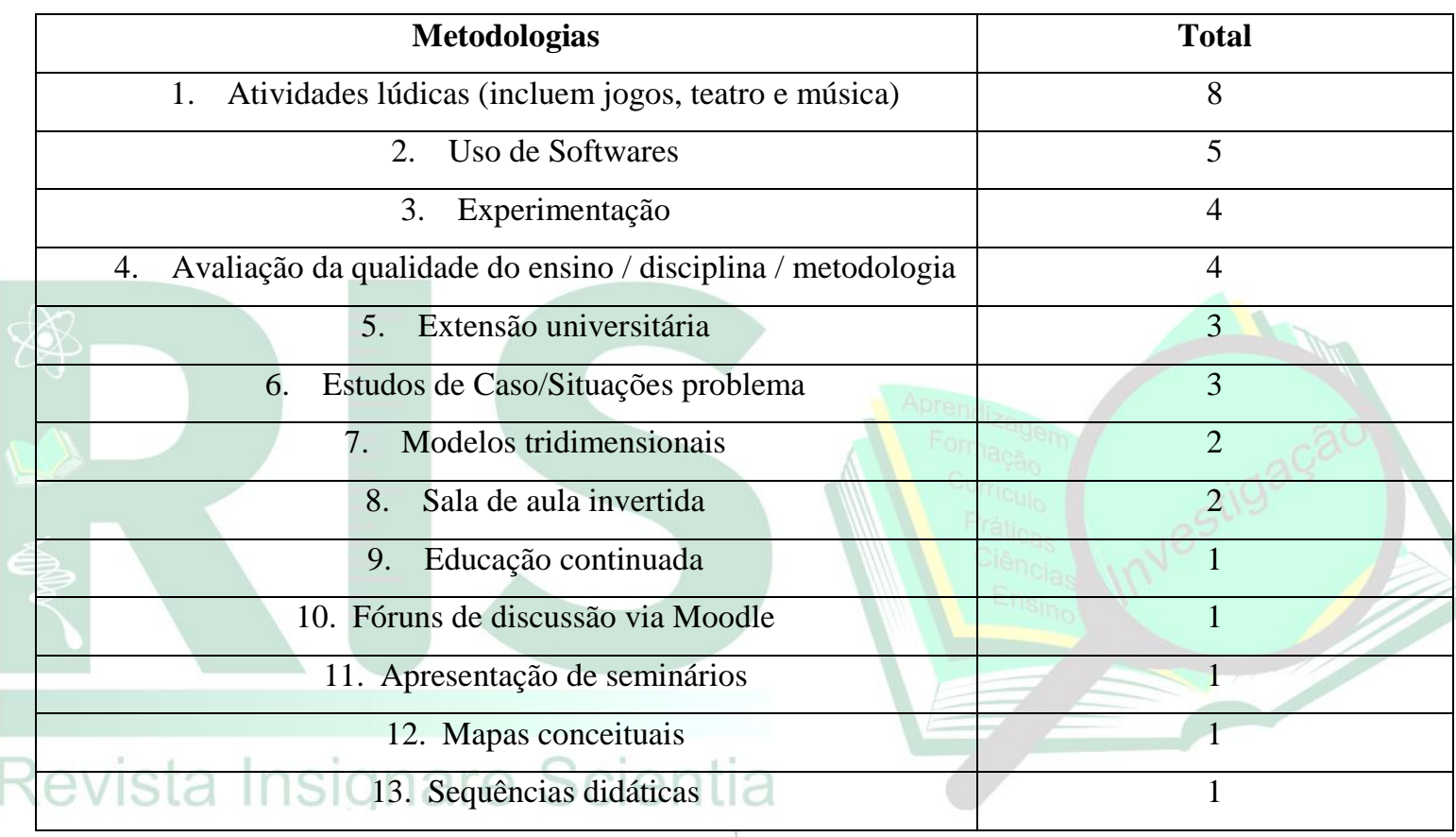

Fonte: os autores, 2019.

No quadro 3 estão representados os artigos que selecionamos para a análise, respeitando os critérios apontados anteriormente. Estão dispostos conforme o título, o ano, os autores, e a seção da revista.

Quadro 3- Artigos que contêm as palavras motivo, motivação, motivar e/motivados publicados na REB entre 2015 a 2019.

\begin{tabular}{|l|l|l|l|l|}
\hline Título Ano & Autores & Seção \\
\hline $\begin{array}{l}\text { 1-Ensino de Imunologia pela incorporação do } \\
\text { conhecimento pelo teatro e a música }\end{array}$ & 2015 & $\begin{array}{l}\text { ALMEIDA, M. E. F.; } \\
\text { SANTOS, V. S. }\end{array}$ & $\begin{array}{l}\text { Pesquisa em } \\
\text { Ensino }\end{array}$ \\
\hline $\begin{array}{l}\text { 2-Seminários: proposta didática para o ensino de Genética } \\
\text { 3-Elaboração e utilização de um aplicativo como } \\
\text { ferramenta no ensino de Bioquímica: carboidratos, }\end{array}$ & 2015 & $\begin{array}{l}\text { ALCÂNTARA, N. R.; } \\
\text { MORAES FILHO, }\end{array}$ & $\begin{array}{l}\text { Inovações } \\
\text { Educacionais }\end{array}$ \\
\hline
\end{tabular}




\begin{tabular}{|c|c|c|c|}
\hline teínas e ácidos nucleicos & & A.V. & \\
\hline $\begin{array}{l}\text { 4-Liga acadêmica de bioquímica clínica: experiência de } \\
\text { implantação e participação na primeira liga acadêmica } \\
\text { numa instituição de ensino superior de Juazeiro do Norte - } \\
\text { Ceará }\end{array}$ & 2015 & $\begin{array}{l}\text { HOLANDA, V. N.; et } \\
\text { al. }\end{array}$ & $\begin{array}{l}\text { Imagem } \\
\text { Pública } \\
\text { Divulgação } \\
\text { Científica da } \\
\text { Bioquímica }\end{array}$ \\
\hline $\begin{array}{l}\text { 5-Análise da percepção de estudantes de graduação da } \\
\text { área da saúde sobre o tema Biologia Celular }\end{array}$ & 2015 & $\begin{array}{l}\text { MONERAT, C. A. A.; } \\
\text { ROCHA, M. B. }\end{array}$ & $\begin{array}{l}\text { Pesquisa em } \\
\text { ensino }\end{array}$ \\
\hline $\begin{array}{l}\text { 6-Um jogo de construção para o aprendizado colaborativo } \\
\text { de Glicólise e Gliconeogênese }\end{array}$ & 2015 & OLIVEIRA, O. S. & $\begin{array}{l}\text { Inovações } \\
\text { educacionais }\end{array}$ \\
\hline $\begin{array}{l}\text { 7-Twister Proteico: uma ferramenta lúdica envolvendo a } \\
\text { síntese de proteínas }\end{array}$ & 2015 & $\begin{array}{l}\text { WEYH, } \\
\text { CARVALHO, } \\
\text { B.; GARNERO, A. V. }\end{array}$ & $\begin{array}{l}\text { Inovações } \\
\text { educacionais }\end{array}$ \\
\hline $\begin{array}{l}\text { 8- Produção científica sobre estratégias didáticas } \\
\text { utilizadas no ensino de Bioquímica: uma revisão } \\
\text { sistemática }\end{array}$ & 2016 & $\begin{array}{l}\text { SILVEIRA, J. } \quad \text { T.; } \\
\text { ROCHA, J. B. T. }\end{array}$ & $\begin{array}{l}\text { Pesquisa em } \\
\text { ensino }\end{array}$ \\
\hline $\begin{array}{l}\text { 9-Unidade Metabólica Baseada em Casos (CBMU): Um } \\
\text { modelo para melhor compreensão do metabolismo no } \\
\text { segundo ano do programa modular extendido de } \\
\text { estudantes de medicina }\end{array}$ & 2016 & $\begin{array}{l}\text { EISSA, } \\
\text { SABBOUR, A. }\end{array}$ & $\begin{array}{l}\text { Inovações } \\
\text { educacionais }\end{array}$ \\
\hline $\begin{array}{l}\text { 10- Jogo Bozó Genético: uma proposta didática como } \\
\text { alternativa para o ensino da replicação do DNA no ensino } \\
\text { médio }\end{array}$ & 2016 & VILHENA, L. et al. & REB na escola \\
\hline $\begin{array}{l}\text { 11- Apresentação de resultados de pesquisa científica } \\
\text { como estratégia para aumentar o interesse dos alunos em } \\
\text { fisiologia }\end{array}$ & 2016 & $\begin{array}{l}\text { ALTERMANN, C. D.; } \\
\text { GARCIA, } \\
\text { AELLO, P. C. }\end{array}$ & $\begin{array}{l}\text { Inovações } \\
\text { educacionais }\end{array}$ \\
\hline $\begin{array}{l}\text { 12- Observação do efeito redutor da } \mathrm{N} \text {-acetilcisteína no } \\
\text { metabolismo da levedura }\end{array}$ & 2016 & CHAPELA, S. et al. & $\begin{array}{l}\text { Inovações } \\
\text { educacionais }\end{array}$ \\
\hline $\begin{array}{l}\text { 13- ProtVirt: simulação da dosagem de proteínas por } \\
\text { espectrometria auxiliando as aulas práticas de Bioquímica }\end{array}$ & 2016 & HORNINK, G. G. & $\begin{array}{l}\text { Inovações } \\
\text { educacionais }\end{array}$ \\
\hline $\begin{array}{l}\text { 14- Impacto do ensino do Ciclo da Ureia por meio do } \\
\text { "vídeo animado" versos o método de retroprojetor: } \\
\text { percepção dos estudantes do primeiro ano de Bacharelado } \\
\text { em odontologia }\end{array}$ & 2017 & $\begin{array}{l}\text { AZIL, A. } \\
\text { SURYAKAR, } \\
\text { DIKSHIT, M. }\end{array}$ & $\begin{array}{l}\text { Pesquisa em } \\
\text { ensino }\end{array}$ \\
\hline $\begin{array}{l}\text { 15- Estudos dirigidos inovadores para a aprendizagem } \\
\text { significativa de bioquímica no curso de biologia: uma } \\
\text { pesquisa baseada em design }\end{array}$ & 2017 & $\begin{array}{l}\text { COSTA. } \quad \text { C.; } \\
\text { GALEMBECK, E. }\end{array}$ & $\begin{array}{l}\text { Pesquisa em } \\
\text { ensino }\end{array}$ \\
\hline $\begin{array}{l}\text { 16- O hormônio insulina como um modelo para ensinar a } \\
\text { estrutura tridimensional das proteínas }\end{array}$ & 2017 & $\begin{array}{l}\text { OLIVEIRA, C. S. et } \\
\text { al. }\end{array}$ & $\begin{array}{l}\text { Inovações } \\
\text { educacionais }\end{array}$ \\
\hline
\end{tabular}




\begin{tabular}{|c|c|c|c|}
\hline $\begin{array}{l}\text { 17- Construção e aplicação de um modelo tridimensional } \\
\text { como recurso didático para o ensino de síntese proteica }\end{array}$ & 2017 & $\begin{array}{l}\text { LAZZARONI, A. A.; } \\
\text { TEIXEIRA, G. A. P. } \\
\text { B. }\end{array}$ & REB na escola \\
\hline $\begin{array}{l}\text { 18- Estratégias didático-pedagógicas como alternativas } \\
\text { para o ensino de Biologia Celular: curso aos professores } \\
\text { de escolas públicas de Ensino Médio de Curitibanos-SC }\end{array}$ & 2017 & $\begin{array}{l}\text { GLASER, } \\
\text { PIERRE, P. } \quad \text { M. } \quad \text { O.; } \\
\text { FIOREZE, A. C. C. L. }\end{array}$ & REB na escola \\
\hline $\begin{array}{l}\text { 19- O uso de fóruns de discussão sobre tópicos de } \\
\text { interesse geral como estratégia para melhorar o interesse } \\
\text { dos estudantes em Fisiologia }\end{array}$ & 2017 & $\begin{array}{l}\text { GONÇALVES, R. et } \\
\text { al. }\end{array}$ & $\begin{array}{l}\text { Pesquisa em } \\
\text { ensino }\end{array}$ \\
\hline $\begin{array}{l}\text { 20- Mapeando tendências da pesquisa na área de } \\
\text { Educação em Bioquímica da SBBq de } 2006 \text { a } 2016\end{array}$ & 2017 & $\begin{array}{l}\text { FERREIRA, C. R. C.; } \\
\text { GONÇALVES, J. L. }\end{array}$ & $\begin{array}{l}\text { Pesquisa em } \\
\text { ensino }\end{array}$ \\
\hline $\begin{array}{l}\text { 21-Avaliação das dificuldades de aprendizado em } \\
\text { Bioquímica dos discentes da Universidade Federal do } \\
\text { Piauí }\end{array}$ & 2017 & $\begin{array}{l}\text { ANDRADE, R. S. B.; } \\
\text { SILVA, A. F. S.; } \\
\text { ZIERER, M. S. }\end{array}$ & $\begin{array}{l}\text { Pesquisa em } \\
\text { ensino }\end{array}$ \\
\hline $\begin{array}{l}\text { 22- Atividades experimentais nos anos iniciais do ensino } \\
\text { fundamental: ferramenta metodológica para a construção } \\
\text { do processo de ensino aprendizagem }\end{array}$ & 2017 & LIMA, A. S. et al. & REB na escola \\
\hline $\begin{array}{l}\text { 23- Uso do Role-Playing Game (RPG) como } \\
\text { complemento didático no ensino de Imunologia }\end{array}$ & 2017 & $\begin{array}{l}\text { LAUREANO, M. O. } \\
\text { L. et al. }\end{array}$ & $\begin{array}{l}\text { Inovações } \\
\text { educacionais }\end{array}$ \\
\hline $\begin{array}{l}\text { 24- Na trilha dos genes: uma proposta de jogo didático } \\
\text { para o ensino de Genética }\end{array}$ & 2018 & LOVATO, F. L. & $\begin{array}{l}\text { Inovações } \\
\text { educacionais }\end{array}$ \\
\hline $\begin{array}{l}\text { 25- Ensino híbrido e gamificação aplicado no ensino de } \\
\text { Bioquímica } \\
\text { evista }\end{array}$ & 2018 & $\begin{array}{l}\text { JUNIOR SOUZA, A. } \\
\text { A.; SOUZA, G. P. V. } \\
\text { A.; SANTOS, E. A. }\end{array}$ & $\begin{array}{l}\text { Inovações } \\
\text { educacionais }\end{array}$ \\
\hline $\begin{array}{l}\text { 26- Resolução de problemas no ensino de Ciências: } \\
\text { utilização de Artemia salina como modelo experimental } \\
\text { para o estudo de plantas medicinais na escola básica }\end{array}$ & 2018 & $\begin{array}{l}\text { SALGUEIRO, A. C. } \\
\text { F.; et al. }\end{array}$ & scola \\
\hline $\begin{array}{l}\text { 27- Ciclo celular: construção e validação de uma } \\
\text { sequência didática pela metodologia da engenharia } \\
\text { didática }\end{array}$ & 2018 & $\begin{array}{l}\text { KIELING, K. M. C.; } \\
\text { GOULART, A. S.; } \\
\text { ROEHRS, R. }\end{array}$ & REB na escola \\
\hline $\begin{array}{l}\text { 28- Percepção de estudantes de graduação de uma } \\
\text { Universidade brasileira sobre a disciplina de Bioquímica }\end{array}$ & 2018 & $\begin{array}{l}\text { NOGARA, P. A.; et } \\
\text { al. }\end{array}$ & $\begin{array}{l}\text { Pesquisa em } \\
\text { ensino }\end{array}$ \\
\hline $\begin{array}{l}\text { 29- Avaliação da qualidade de ensino de Bioquímica em } \\
\text { cursos de Nutrição }\end{array}$ & 2018 & $\begin{array}{lrr}\text { SILVEIRA, } \quad \text { J. } & \text { T.; } \\
\text { TEIXEIRA, J. B. } & \end{array}$ & $\begin{array}{l}\text { Pesquisa em } \\
\text { ensino }\end{array}$ \\
\hline 30- Realidade virtual no ensino de vias metabólicas & 2018 & $\begin{array}{l}\text { GARZÓN, J. C. } \quad \text { V.; } \\
\text { MAGRINI, } \quad \text { M. } \\
\text { L.; } \\
\text { GALEMBECK, E. }\end{array}$ & $\begin{array}{l}\text { Inovações } \\
\text { educacionais }\end{array}$ \\
\hline 31- Estratégia de ensino: Aprenda em sala de aula & 2018 & $\begin{array}{l}\text { SANTIAGO, S. A.; } \\
\text { CARVALHO, H. F. }\end{array}$ & $\begin{array}{l}\text { Inovações } \\
\text { educacionais }\end{array}$ \\
\hline
\end{tabular}




\begin{tabular}{|c|c|c|c|}
\hline $\begin{array}{l}\text { 32- Liga Acadêmica de Fisiologia Médica: um olhar dos } \\
\text { discentes sobre metodologias ativas de ensino- } \\
\text { aprendizagem }\end{array}$ & 2019 & FRIZZO, R. A.; et al. & $\begin{array}{l}\text { Pesquisa em } \\
\text { ensino }\end{array}$ \\
\hline $\begin{array}{l}\text { 33- Análise do conhecimento dos acadêmicos das áreas } \\
\text { biológicas e saúde sobre o dogma "DNA - RNA - } \\
\text { Proteína" }\end{array}$ & 2019 & $\begin{array}{l}\text { ANDRADE, V. R. M.; } \\
\text { et al. }\end{array}$ & $\begin{array}{l}\text { Pesquisa em } \\
\text { ensino }\end{array}$ \\
\hline $\begin{array}{l}\text { 34- As aventuras de Kreber: jogo digital sobre o } \\
\text { metabolismo energético }\end{array}$ & 2019 & $\begin{array}{l}\text { BAÊTA, F. J. M.; } \\
\text { HORNINK, G. G. }\end{array}$ & $\begin{array}{l}\text { Inovações } \\
\text { educacionais }\end{array}$ \\
\hline $\begin{array}{l}\text { 35- Ferramentas de bioinformática aplicadas ao ensino da } \\
\text { biotecnologia }\end{array}$ & 2019 & $\begin{array}{l}\text { NASCIMENTO, Y. A. } \\
\text { P.; SARAIVA, F. M. }\end{array}$ & REB na escola \\
\hline $\begin{array}{l}\text { 36- Mês do cérebro: uma ação visando a popularização da } \\
\text { neurociência com alunos de ensino médio, em uma escola } \\
\text { do DF, Brasil }\end{array}$ & 2019 & $\begin{array}{l}\text { CARVALHO, K. M.; } \\
\text { MENEZES, J. P. C. }\end{array}$ & $\begin{array}{l}\text { Imagem } \\
\text { pública } \\
\text { divulgação } \\
\text { científica. }\end{array}$ \\
\hline
\end{tabular}

Fonte: os autores, 2019.

\subsection{Motivos relacionados à interação social}

Na perspectiva da psicologia histórico-cultural a atividade de estudo antes de ser individual é social, as interações sociais desencadeiam a aquisição do conhecimento e o desenvolvimento humano, especialmente através da comunicação entre as pessoas e pelo uso de instrumentos (LEONTIEV, 1978).

Esses elementos criam a possibilidade de reorganizar as ideias que os estudantes já possuem e favorece a construção de novos conhecimentos. A interação social nesta perspectiva, "não tem sentido de adaptação ao meio, mas de diálogo, de participação consciente, de possibilidade de intervenção" (SFORNI, 2004, p. 11), tem função formadora.

Os artigos que contemplam esta categoria de motivos envolvem as seguintes metodologias: o teatro e a música (Artigo 1), extensão universitária (Artigos 4, 11, 32), estudos de caso (Artigos 9, 15, 20), formação continuada (Artigo 18), fóruns de discussão (artigo 19), atividades lúdicas/jogos (Artigos 6, 7, 10, 23, 24, 34 e 36). Estas metodologias criam conexões entre as pessoas e realidade das futuras práticas profissionais, estimulando a necessidade de aprendizado de Bioquímica e áreas afins.

O teatro e a música são formas lúdicas de ensinar e aprender. O artigo 1 (ALMEIDA; SANTOS, 2015) demonstrou que este método implica na responsabilidade 
dos "atores" e "telespectadores" contribuindo para a construção de um pensamento crítico, bem como para a formação social e cultural dos alunos que têm a oportunidade de prestigiá-lo. Através das narrativas que são desencadeadas nesta metodologia tem-se a oportunidade de colocar o pensamento em palavras tornando a universidade em um espaço de socialização do conhecimento (BOLZAN, 2009).

No artigo 4 (2015) a extensão universitária é uma metodologia que aproxima os estudantes das suas profissões. Conforme Holanda et. al (2015, p. 94), uma das principais motivações apontadas pelos participantes foi "o desejo de atuar de forma mais direta na comunidade, através de ações sociais". Os autores concluem que a criação da Liga acadêmica foi extremamente positiva, possibilitando "uma extensa contribuição sócio-científica aos participantes considerando a vivência com o social, os novos conhecimentos científicos e clínicos” (Ibidem, p. 98).

O artigo 18 (GLASER; PIERRE; FIOREZE, 2017) refere-se à formação continuada de professores, a qual permitiu a troca de experiências através da elaboração de modelos didáticos para ensinar Biologia celular. A interação social foi um dos fatores que motivou os professores a buscarem por estratégias didáticas mais atrativas, pois propiciou um ambiente de discussão de práticas pedagógicas.

No artigo 19 (GONÇALVES et al; 2017) também é possível observar, que a metodologia de fóruns de discussão é utilizada como estratégia para melhorar o interesse dos estudantes e estimular o pensamento crítico.

As metodologias de estudo de casos clínicos e apresentação de trabalhos científicos como as descritas nos artigos 9 (EISSA; SABBOUR, 2016) e 11 (ALTERMANN; GARCIA; MELLO, 2016) respectivamente, aproximam os alunos da realidade profissional e são utilizadas para melhorar as capacidades intelectuais, possibilitando desenvolver as habilidades de pensamento crítico nos estudantes, pois geram discussão dos dados analisados.

Podemos inferir que esta categoria de motivos é caracterizada pela atividade compartilhada, que estimula as capacidades de atenção, memória, abstração e generalização que são desencadeadas no meio social, cultural, através da comunicação entre as pessoas. A apropriação do conhecimento, ou seja, o desenvolvimento cognitivo 
vai da dimensão social para a individual e vice-versa (SFORNI, 2004), destacando a importância da interação social nos processos de ensino e aprendizagem.

\subsection{Aprendizagem ativa}

Leontiev estudou o aparecimento da consciência humana em comparação ao aparecimento do trabalho. Em sua obra "O desenvolvimento do psiquismo" (LEONTIEV, 1978), o autor assinala que o trabalho se efetua em condições de atividade coletiva, orientados por uma necessidade e efetivados pelo uso de instrumentos. Assim como o trabalho, a atividade estudo passou a ser considerada uma atividade social que exige organização do processo didático e educativo e o uso de instrumentos a fim de satisfazer uma necessidade de aprendizagem, transformando o conteúdo externo em mental e social em individual.

Diferente do ensino tradicional, metodologias ativas de ensino tem o aluno como principal agente responsável por sua aprendizagem e o professor um facilitador deste processo, elas favorecem a autonomia dos estudantes e apresentam oportunidades de problematização (BERBEL, 2011). Os motivos relacionados à aprendizagem ativa constituem ações e operações que possibilitam desencadear nos alunos o desenvolvimento do pensamento, por meio da reflexão e análise coletiva.

Nesta categoria de motivos destacamos metodologias didáticas como a aprendizagem baseada em problemas (Artigos 9,15 e 20), construção de modelos didáticos (Artigos 16 e 17), experimentação (Artigos 5, 12, 22 e 26), jogos (Artigos 6, 7, 10, 23,24, 34 e 36), sala de aula invertida (Artigos 25 e 31), uso de softwares (Artigos 3 , 13, 14, 30 e 35), mapas conceituais (Artigo 33) e sequências didáticas (Artigo 27).

Conforme o artigo 15 (COSTA; GALEMBECK, 2017), a metodologia de resolução problemas permite despertar a curiosidade dos alunos na busca por solucioná-las, os alunos elaboram hipóteses que são discutidas em grupos com a ajuda do professor. Os autores destacam que para ensinar Bioquímica, “é indispensável o uso de estratégias motivacionais voltadas para cada público-alvo, com o objetivo de contextualizar o assunto para despertar interesse, estudo rápido e promover o aprendizado" (COSTA; GALEMBECK, 2017, p. 76).

O principal propósito da aprendizagem baseada em problemas é criar hábitos de estudo e de pensamento pela experiência reflexiva, principalmente a autonomia de 
aprendizagem e trabalho em equipe (FREITAS, 2012). Esta metodologia é considerada ativa, interativa e colaborativa visando criar possibilidades de desenvolvimento argumentativo.

A construção de modelos didáticos tridimensionais promove a aprendizagem ativa como demonstrado no artigo 16. Oliveira et al (2017) consideram que elaboração de um modelo tridimensional para ensinar as estruturas de proteínas promove o aprendizado, pois os alunos interagem com modelos concretos sobre assuntos abstratos e precisam sair da sua zona de conforto, ou seja, tornam-se ativos na elaboração do modelo e assim, consequentemente tornam-se mais motivados. O artigo 16 (OLIVEIRA et al, 2017) conclui que a construção de modelos tridimensionais gera resultados significativos e as dificuldades de aprendizagem de conceitos abstratos são superadas por meio da atividade que é realizada em colaboração.

A característica lúdica dos jogos didáticos, como no exemplo do artigo 34 (BAÊTA; HORNINK, 2019), aproxima os alunos e o professor, de maneira semelhante com a metodologia de construção de modelos tridimensionais que implica a participação ativa. Os autores concluem que a partir do uso do jogo, "observou-se que os usuários puderam, de forma lúdica, interagir ativamente com os conteúdos abordados e, por meio das dificuldades apresentadas no jogo, tiveram a oportunidades de ampliar e rever seus conhecimentos" (BAÊTA; HORNINK, 2019, p. 33).

A experimentação também está relacionada à aprendizagem ativa, como destacamos nos artigos 22 (2017) e 26 (2018).

No artigo 22, Lima et al (2017) consideram a experimentação um fator que motiva e auxilia fortemente a aprendizagem, a memorização e mudança conceitual. Para os autores a participação ativa dos alunos pode acionar uma série de estruturas cerebrais associadas com a cognição e evidenciam que "motivação, envolvimento e experimentação são elementos de um mesmo viés educacional e se apresentam como indispensáveis na ação pedagógica" (Ibidem, 2017, p. 55).

Os autores do artigo 26 (2018) relatam que os alunos consideram o ensino por experimentação mais atraente e produtivo e justificam dizendo que "isso ocorre especialmente pelo fato de o estudante participar ativamente de seu processo de 
aprendizado, ao tentar solucionar os problemas apresentados pelo confronto direto com a realidade" (SALGUEIRO, et al, 2018, p. 45).

O Artigo 10 (VILHENA, et al, 2016) trata os jogos didáticos como instrumentos úteis para instigar a curiosidade e a criatividade dos alunos.

A metodologia de sala de aula invertida provoca a inversão da postura do professor e do aluno. Conforme descrito no artigo 25 (JUNIOR SOUZA; SOUZA; SANTOS, 2018), o professor assume uma postura de orientador e facilitador e o aluno sai da postura de expectador para um perfil mais ativo e colaborativo, contribuindo para a aprendizagem.

O uso de softwares como o descrito no artigo 35 (NASCIMENTO; SARAIVA, 2019) é considerado pelos autores um material didático dinâmico. Eles destacam que a simples utilização de um software (bioinformática) já desperta a curiosidade e produz melhores resultados na aprendizagem.

Ainda mapas conceituais e sequências didáticas representados no artigo 33 (ANDRADE, et al, 2019) e no artigo 27 (KIELING; GOULART; ROEHRS, 2018), respectivamente, são ferramentas de ensino que colocam os alunos numa condição ativa de aprendizagem, pois diferente das aulas tradicionais, são os alunos que desenvolvem a aula.

Cada metodologia inclusa nesta categoria de motivos tem sua peculiaridade, mas percebemos que apesar das diferenças, a grande maioria busca colocar o aluno no centro da aprendizagem através da resolução de problemas e desafios que mobilizem o potencial intelectual. Assim é possível que ocorra o desenvolvimento do pensamento científico e reflexivo, contribuindo para a autonomia dos estudantes (BERBEL, 2011).

\subsection{Desempenho acadêmico}

Destacamos nesta categoria de motivos relacionados ao desempenho acadêmico os artigos $(2,8,21,28$ e 29) que avaliaram a qualidade do ensino, as disciplinas e as metodologias didáticas utilizadas para ensinar bioquímica e áreas afins.

A avaliação faz parte do cotidiano dos alunos e professores em qualquer sistema de ensino e, portanto, o desempenho acadêmico é um dos motivos melhor observado 
quando nos referimos à educação e pode estar relacionado a um sistema de recompensas, normalmente a busca da aprovação.

Leontiev (1978) descreve o exemplo de um aluno fazendo a leitura de uma obra científica em preparação para uma avaliação:

\begin{abstract}
Imaginemos um aluno lendo uma obra científica que lhe foi recomendada. Eis um processo consciente que visa um objetivo preciso. O seu fim consciente é assimilar o conteúdo da obra. Mas qual é o sentido particular que toma para o aluno este fim e por consequência a ação que lhe corresponde? Isso depende do motivo que estimula a atividade realizada na ação da leitura. Se o motivo consiste em preparar o leitor para a sua futura profissão, a leitura terá um sentido. Se, em contrapartida, se trata para o leitor de passar nos exames, que não passam de uma simples formalidade, o sentido da sua leitura será outro, ele lerá a obra com outros olhos; assimilá-la-á de maneira diferente (LEONTIEV, 1978, p. 97).
\end{abstract}

O autor continua narrando que outro aluno comenta ser desnecessária a leitura da obra, pois não fará parte da avaliação. Temos, portanto, algumas situações: este aluno pode simplesmente parar a leitura, pode continuar porque estava achando interessante ou ainda, ler porque será útil para sua profissão futura. Esses motivos nos fazem refletir sobre a intencionalidade dos professores ao propor uma atividade, exercício, experimento e avaliação.

Além do sistema de recompensas, o desempenho do indivíduo pode mudar à medida que ele atua com outros sujeitos no processo de ensino e de aprendizagem. Bolzan $(2009$, p. 41) enfatiza que precisamos considerar as experiências vividas pelo individuo, portanto, "a bagagem sociocultural de cada sujeito é um fator que distingue suas condições para aprender durante as situações de ensino”.

O artigo 2 (GOLVÊA, 2015) se destaca ao demonstrar claramente essa categoria de motivos. Na metodologia descrita, foi proposta aos alunos a apresentação de seminários sobre um determinado assunto, sendo aberto para comunidade acadêmica. Conforme a autora, a execução dos seminários não proporcionou ganho de conhecimento para todas as turmas analisadas e um dos motivos poderia estar relacionado com a avalição.

Na proposta Golvêa (2015), os alunos tinham a liberdade de escolher se os seminários iriam fazer parte do sistema de notas da disciplina ou não. Os resultados indicaram que os grupos que optaram por não fazer parte da nota demonstraram desinteresse pela proposta, ao contrário dos grupos em que esta atividade integrou a avaliação. 
No artigo 21 (ANDRADE; SILVA; ZIERER, 2017) foram analisadas múltiplas causas para dificuldades de aprendizagem em Bioquímica, mas enfatizou-se como mais importante à deficiência na educação básica. Os autores também destacaram que a rotina de estudos inadequada contribui para o baixo desenvolvimento acadêmico. Além disso, sugerem que diferentes atividades podem facilitar o ensino e aprendizado, tornando-se mais atrativas aos alunos.

Os artigos 8, 28 e 29 apontam que disciplinas como a Bioquímica precisam se adequar com as características dos cursos, dando ênfase as profissões. No artigo 28 (NOGARA, et al, 2018) analisou-se diferentes metodologias utilizadas para ensinar Bioquímica, no entanto, os autores concluem que apesar de existirem diversos trabalhos que versam sobre metodologias didáticas diferenciadas há poucos estudos que analisam a efetividade do aprendizado propriamente dito.

Assim, essa categoria demonstrou que existem grandes esforços para elevar os níveis de aprendizagem dos alunos, mas que o desempenho acadêmico ainda é mensurado apenas por notas, sendo mais difícil evitar as avaliações tradicionais e consequentemente validar outras metodologias para mensurar os níveis de aprendizagem dos alunos.

\section{CONCLUSÃO}

Neste estudo, verificamos que a escolha por metodologias diferenciadas no ensino de Bioquímica e de áreas afins, se justifica pelas dificuldades de aprendizagem apresentadas, principalmente pela necessidade de compreensão dos conteúdos abstratos em um curto espaço de tempo. Percebemos que apesar de existirem inúmeros motivos que versam sobre os processos de ensino e de aprendizagem, muitas vezes, não compreendemos o significado conceitual dos motivos elencados.

Embora não estejam explícitos nos textos analisados quais são os significados destes motivos, acreditamos que a justificativa possa estar relacionada com a perspectiva da psicologia histórico-cultural do desenvolvimento humano. Por esse viés destacamos os motivos relacionados à interação social, a aprendizagem ativa e ao desempenho acadêmico. 
Portanto, levando em consideração os aspectos apontados ao longo do texto, enfatizamos a complexidade que é ensinar e aprender Bioquímica e outras áreas, e, ressaltamos que nenhum dos motivos apontados deve ser pensado isoladamente. Os profissionais responsáveis pelo ensino necessitam prestar atenção nas escolhas metodológicas e em como essas escolhas vão refletir positivamente ou negativamente no aprendizado dos alunos.

Nesse sentido, concluímos que embora haja a intenção de interrelacionar as metodologias didáticas com a eficácia do aprendizado, ainda não conseguimos aferir se houve um aprendizado real de médio e longo prazo com as metodologias utilizadas nos artigos citados aqui. Sugerimos que a forma de avaliação decorrente destes instrumentos seja mais eficiente, que a motivação seja pela necessidade de aprender, e sim, que esteja relacionada com a interação social, a aprendizagem ativa e o desempenho acadêmico.

\section{REFERÊNCIAS BIBLIOGRÁFICAS}

ALMEIDA, M. E. F.; SANTOS, V. S. Ensino de Imunologia pela incorporação do conhecimento pelo teatro e a música. Revista de ensino de Bioquímica, v. 13, n. 3, 2015, pp. 06-20.

ALTERMANN, C. D.; GARCIA, A.; MELlO, P. C. Apresentação de resultados de pesquisa científica como estratégia para aumentar o interesse dos alunos em fisiologia. Revista de ensino de Bioquímica, v. 14, n. 1, 2016, pp. 90-98.

ANDRADE, V. R. M.; et al. Análise do conhecimento dos acadêmicos das áreas biológicas e saúde sobre o dogma "DNA - RNA - Proteína". Revista de ensino de Bioquímica, v. 17, n. 1, 2019, pp. 1-15.

ANDRADE, R. S. B.; SILVA, A. F. S.; ZIERER, M. S. Avaliação das dificuldades de aprendizado em Bioquímica dos discentes da Universidade Federal do Piauí. Revista de ensino de Bioquímica, v. 15, n. 1, 2017, pp. 24-39.

BAÊTA, F. J. M; HORNINK, G. G. As aventuras de Kreber: jogo digital sobre o metabolismo energético. Revista de ensino de Bioquímica, v. 17, n. 1, 2019, pp. 1636.

BERBEL, N. As metodologias ativas e a promoção da autonomia de estudantes. Semina: Ciências Sociais e Humanas, Londrina, v. 32, n. 1, p. 25-40, jan./jun. 2011.

BOLZAN, D. Formação de professores: Compartilhando e reconstruindo conhecimentos. Porto Alegre: Mediação, 2002.

BONOTTO, D.; SCHELLER, M. O agir modelagem. Revista Insignare Scientia RIS, v. 1, n. 2, 20 jun. 2018.

CALVE, T. M.; ROSSLER, J. H.; SILVA, G. L. R. A aprendizagem escolar e o sentido pessoal na Psicologia de A. N. Leontiev. Revista Quadrimestral da Associação 
Brasileira de Psicologia Escolar e Educacional. v.19, n. 3, Set/Dez 2015, pp. 435444.

EISSA, S.; SABBOUR, A. Unidade Metabólica Baseada em Casos (CBMU): Um modelo para melhor compreensão do metabolismo no segundo ano do programa modular extendido de estudantes de medicina. Revista de ensino de Bioquímica, v. 14, n. 3, 2016, pp. 22-33.

FREITAS, R. A. M. M. Ensino por problemas: uma abordagem para o desenvolvimento do aluno. Educação e Pesquisa, São Paulo, v. 38, n. 2, p. 403-418, abr./jun. 2012. Acesso em 17 jul. 2019. Disponível em: http://www.scielo.br/pdf/ep/v38n2/aop478.pdf

GLASER, V.; PIERRE, P. M. O.; FIOREZE, A. C. C. L. Estratégias didáticopedagógicas como alternativas para o ensino de Biologia Celular: curso aos professores de escolas públicas de Ensino Médio de Curitibanos-SC. Revista de ensino de Bioquímica, v. 15, n. 2, 2017, pp. 49-74.

GOLVÊA, C. M. C. P. Seminários: proposta didática para o ensino de Genética. Revista de ensino de Bioquímica, v. 13, n. 3, 2015, pp. 22-35.

GONÇALVES, R. et al. O uso de fóruns de discussão sobre tópicos de interesse geral como estratégia para melhorar o interesse dos estudantes em Fisiologia. Revista de ensino de Bioquímica, v. 15, n. 1, 2017, pp. 06-14.

HOLANDA, V. N. et al. Liga acadêmica de bioquímica clínica: experiência de implantação e participação na primeira liga acadêmica numa instituição de ensino superior de Juazeiro do Norte -Ceará. Revista de ensino de Bioquímica, v. 13, n. 3, 2015, pp. 87-99.

JUNIOR SOUZA, A. A.; SOUZA, G. P. V. A.; SANTOS, E. A. Ensino híbrido e gamificação aplicado no ensino de Bioquímica. Revista de ensino de Bioquímica, v. 16, n. 2, 2018, pp. 87-103.

KIELING, K. M. C; GOULART, A. S.; ROEHRS, R. Ciclo celular: construção e validação de uma sequência didática pela metodologia da engenharia didática. Revista de ensino de Bioquímica, v. 16, n. 2, 2018, pp. 49-70.

LEONTIEV, A. O desenvolvimento do psiquismo humano. Lisboa: Horizonte universitário. 1978.

Actividade, conciencia, personalidad. $2^{\mathrm{a}}$ reimpresión. Ciudad de La Habana: Editorial Pueblo e Educación, 1985.

LIMA, A. S. et al. Atividades experimentais nos anos iniciais do ensino fundamental: ferramenta metodológica para a construção do processo de ensino aprendizagem. Revista de ensino de Bioquímica, v. 15, n. 2, 2017, pp. 40-63.

LOMPSCHER, J. Motivation and activity. European Journal of Psychology of Education, 1999, Vol.XIV, ${ }^{\circ} 1$, pp.11-22.

MARINO FILHO, Armando. A atividade de estudo no ensino fundamental: necessidade e motivação. Marília, 2011, 236 f. Tese (Doutorado em Educação) Faculdade de Filosofia e Ciências, Universidade Estadual Paulista, 2011. 
MORAES, R. Uma tempestade de luz: a compreensão possibilitada pela análise textual discursiva. Ciência \& Educação, v. 9, n. 2, p. 191-211, 2003. Acesso em 03 out. 2019. Disponível em http://dx.doi.org/10.1590/S1516-73132003000200004.

NASCIMENTO, Y. A. P.; SARAIVA, L. F. M. Ferramentas de bioinformática aplicadas ao ensino da biotecnologia. Revista de ensino de Bioquímica, v. 15, n. 2, 2019, pp. 77-90.

NOGARA, P. A.; et al. Percepção de estudantes de graduação de uma Universidade brasileira sobre a disciplina de Bioquímica. Revista de ensino de Bioquímica, v. 16, n. 1, 2018, pp. 5-24.

OLIVEIRA, C. S. et al. O hormônio insulina como um modelo para ensinar a estrutura tridimensional das proteínas. Revista de ensino de Bioquímica, v. 17, n. 1, 2019, pp. 114-130.

REVISTA DE ENSINO DE BIOQUÍMICA. ISSN: 2318-8790, 2015-2019.

SALGUEIRO, A. C. F. et. al. Resolução de problemas no ensino de Ciências: utilização de Artemia salina como modelo experimental para o estudo de plantas medicinais na escola básica. Revista de ensino de Bioquímica, v. 16, n. 2, 2018, pp. 31-47.

SEVERINO, A. J. Metodologia do trabalho científico. $23^{\text {a }}$ edição. São Paulo: Cortez Editora, 2007.

SFORNI, M. S. F. Aprendizagem conceitual e organização do ensino: contribuições da teoria da atividade. Araraquara: JM Editora, 2004, p.200.

SILVEIRA, J. T; ROCHA, J. B. T. Produção científica sobre estratégias didáticas utilizadas no ensino de Bioquímica: uma revisão sistemática. Revista de ensino de Bioquímica, v. 14, n.1, 2016, pp. 07-21.

VIGOTSKI, L. S. A construção do pensamento e da linguagem. Tradução Paulo Bezerra. São Paulo: Martins Fontes, 2001. p.496.

A formação social da mente. Tradução José Cipolla Neto, Luís Silveira Menna Barreto, Solange Castro Afeche. 6. ed. São Paulo: Martins Fontes, 2002.

; LURIA, A; R. LEONTIEV, A. N. Linguagem, desenvolvimento e aprendizagem. Tradução: Maria da Pena Villalobos. 14ª ed. São Paulo: Ícone, 2016.

VILHENA, L. et al. Jogo Bozó Genético: uma proposta didática como alternativa para o ensino da replicação do DNA no ensino médio. Revista de ensino de Bioquímica, $v$. 14, n. 3, 2016, pp. 57-67. 